Article

\title{
Photodegradation of 1-Butyl-3-methylimidazolium Chloride [Bmim]Cl via Synergistic Effect of Adsorption-Photodegradation of $\mathrm{Fe}-\mathrm{TiO}_{2} / \mathrm{AC}$
}

\author{
Azhar Zawawi (D), Raihan Mahirah Ramli * (D) and Noorfidza Yub Harun \\ Department of Chemical Engineering, Universiti Teknologi PETRONAS, 32610 Bandar Seri Iskandar, \\ Perak, Malaysia; azharz.utp@gmail.com (A.Z.); noorfidza.yub@utp.edu.my (N.Y.H.) \\ * Correspondence: raihan.ramli@utp.edu.my; Tel.: +60-53-687-553
}

Received: 24 October 2017; Accepted: 11 December 2017; Published: 14 December 2017

\begin{abstract}
Ionic liquids (ILs) have attracted interest among researchers due to their tunable properties, which enable them to be used in a wide variety of applications. However, toxicity and biodegradation studies of ILs proved that most of the aromatic ILs, such as imidazolium, are highly toxic and non-biodegradable. Researchers have investigated several advance oxidation processes (AOPs) in order to evaluate the efficiency of the systems used to remove ILs from wastewater. However, their relatively high cost and environmental concerns have limited the application of these AOPs in industry. This research conducted a photocatalytic study using hybrid nanomaterials to evaluate the efficiency of this system as an alternative AOP system for the removal of ILs from wastewater. The synergistic effect of adsorption-photodegradation was introduced by depositing $\mathrm{Fe}-\mathrm{TiO}_{2}$ onto functionalized activated carbon (AC). Nano- $\mathrm{TiO}_{2}$ was synthesized using the microemulsion method, then modified with a transition metal, and deposited onto oxidized AC. The photodegradation reaction of 1-butyl-3-methylimidazolium chloride [bmim] $\mathrm{Cl}$ was then investigated under simulated visible light irradiation. It was observed that the overall efficiency of the system increased with the increasing amount of Fe loading. Our investigation revealed that extrinsic factors such as solution $\mathrm{pH}$, the initial concentration of ILs, and photocatalyst dosage significantly affect the overall efficiency of the system. The optimum condition for the system was observed at $\mathrm{pH} 10$, with initial ILs at $1 \mathrm{mM}$ at $1 \mathrm{~g} / \mathrm{L}$ of photocatalyst. The best performance photocatalyst was $0.2 \mathrm{Fe}-\mathrm{TiO}_{2} / \mathrm{AC}$.
\end{abstract}

Keywords: photodegradation; $\mathrm{TiO}_{2}$; ionic liquids; activated carbon; synergistic effect

\section{Introduction}

Ionic liquids (ILs) are chemicals that can be synthesized via the metathetic exchange of anion, neutralization with Brønsted acid, direct alkylation and alkylimidazole, or a carbonate route [1]. Depending on its specific applications, the physical and chemical properties of ILs are tunable by varying its cation and anion. ILs are currently being used in industry for both large-scale production and pilot plant studies. For instance, Petroliam Nasional Berhad (PETRONAS) has applied ILs for mercury removal processes, while BASF and the Institutes Francis de Petrole Axens (IFP) have employed ILs in biphasic acid scavenging ionic liquids (BASIL) process and dimersol process, respectively [2].

The increasing number of IL applications has raised concerns regarding the impact of ILs on the environmental due to its high solubility and resistivity in water. A few researchers who conducted biodegradation studies on ILs concluded that ILs with an aromatic ring cation, such as imidazolium, are non-biodegradable [3-5]. Yet, this type of IL has been widely used in bio-industry [1]. Hence, an efficient treatment system that is able to overcome the high solubility properties of ILs in water is urgently required. Advance oxidation processes (AOPs) are widely known for its high efficiency to 
degrade wide range of organic pollutants [6]. Photocatalytic degradation employing a semiconductor as the photocatalyst is one of the AOPs that efficiently degrades ILs in wastewater [7]. This process can be considered relatively low cost and sustainable, since it is able to convert renewable solar energy into a chemical reaction [8].

Among the semiconductors available for this application, titania $\left(\mathrm{TiO}_{2}\right)$ is the most researched semiconductor that is used as a photocatalyst [9]. However, the major drawback of $\mathrm{TiO}_{2}$ that hinders its application in industry as a photocatalyst is its limited range of UV light absorption. In addition, $\mathrm{TiO}_{2}$ has a comparatively slow diffusion rate between the target pollutant and its surface $[10,11]$. These limitations could be overcome through the modification of $\mathrm{TiO}_{2}$ via several methods, such as modification with metals, depositing $\mathrm{TiO}_{2}$ onto activated carbon (AC) as a support or coupling another semiconductor onto $\mathrm{TiO}_{2}$ as a co-catalyst $[12,13]$. The introduction of metal loadings onto $\mathrm{TiO}_{2}$ has significantly enhanced its activity under visible light, thus improving the overall performance of the system [9]. The modification process causes defects to the $\mathrm{TiO}_{2}$ structure such as oxygen vacancy $\left(\mathrm{V}_{\mathrm{o}}\right)$ and $\mathrm{Ti}^{3+}$, which lead to the reduction of band gap energy. Hence, the absorbance of $\mathrm{TiO}_{2}$ is shifted towards the visible light region [14].

Furthermore, the addition of activated carbon to $\mathrm{TiO}_{2}$ has a dual function: as a support, and at the same time, as the center of accumulation for the pollutant. The presence of hydroxyl groups $(-\mathrm{OH})$ on the AC surface is able to attract 1-butyl-3-methylimidazolium chloride $([\mathrm{bmim}] \mathrm{Cl})$ towards the surface of the photocatalyst, and thus enhances the diffusion rate of $[\mathrm{bmim}] \mathrm{Cl}$ into $\mathrm{TiO}_{2}$. The synergistic effect of the adsorption-photodegradation of the composite photocatalyst consequently increases the overall efficiency of the system [15]. Apart from intrinsic factors, the extrinsic factors such as the initial ILs concentration, the initial $\mathrm{pH}$ of the ILs solution, and photocatalyst dosage have been reported to have significant effects on the overall efficiency of the systems [16].

In this paper, the work is focused on the development of hybrid nano-photocatalysts that consist of nano- $\mathrm{TiO}_{2}$ synthesized via the microemulsion method, modified with $\mathrm{Fe}$, and deposited onto the $\mathrm{AC}$ surface. The efficiency of the developed photocatalyst was evaluated in a photocatalytic degradation system containing [bmim] $\mathrm{Cl}$ solution at the desired concentration under a 500-W visible light energy source. Several parameters that were reported to be highly significant to the photodegradation process will be investigated.

\section{Materials and Methods}

\subsection{Materials}

All of the chemicals were purchased and used without further purification. Hexanol $\left(\mathrm{C}_{6} \mathrm{H}_{14} \mathrm{O}, 98 \%\right)$, iron (III) nitrate nonahydrate $\left(\mathrm{Fe}\left(\mathrm{NO}_{3}\right)_{3} \cdot 9 \mathrm{H}_{2} \mathrm{O}\right)$, 1-butyl-3-methylimidazolium chloride, [bmim] $\mathrm{Cl}\left(\mathrm{C}_{8} \mathrm{H}_{15} \mathrm{ClN}_{2}\right)$, heptane $\left(\mathrm{C}_{7} \mathrm{H}_{16}, 99 \%\right)$, Ethanol $\left(\mathrm{C}_{2} \mathrm{H}_{3} \mathrm{OH}, 95 \%\right)$ and titanium tetraisopropoxide (TTIP, $\mathrm{C}_{12} \mathrm{H}_{28} \mathrm{O}_{4} \mathrm{Ti}$, 97\%) were purchased from Merck (Darmstadt, Germany). Meanwhile, other chemicals such as nitric acid $\left(\mathrm{HNO}_{3}, 65 \%\right)$, triton $\mathrm{X}-100\left(\mathrm{C}_{34} \mathrm{H}_{62} \mathrm{O}_{11}, \mathrm{AR}\right)$, potassium dihydrogen phosphate $\left(\mathrm{KH}_{2} \mathrm{PO}_{4}\right)$, phosphoric acid $\left(\mathrm{H}_{3} \mathrm{PO}_{4}, 85 \%\right)$ and triethylamine $\left(\mathrm{C}_{6} \mathrm{H}_{15} \mathrm{~N}\right.$, $\left.\mathrm{AR}\right)$ were supplied by R\&M Chemicals (Semenyih, Malaysia)

\subsection{Methods}

Nano- $\mathrm{TiO}_{2}$ was synthesized using the water-in-oil microemulsion method, as reported in a previous study [7], followed by modification with the desired Fe via the wetness impregnation method. The resultant powder from the impregnation method was calcined at $400{ }^{\circ} \mathrm{C}$ for $1.5 \mathrm{~h}$. In a different set-up, the pre-carbonized $\mathrm{AC}$ was oxidized using $1 \mathrm{M}$ of nitric acid in a boiling condition for $20 \mathrm{~min}$. The oxidized AC was washed repeatedly with distilled water until the filtrate became neutral. The oxidized $\mathrm{AC}$ was then dried overnight in an oven at $80{ }^{\circ} \mathrm{C}$. Finally, the developed $\mathrm{Fe}-\mathrm{TiO}_{2}$ and $\mathrm{AC}$ were mixed (10 $\mathrm{wt} \% \mathrm{AC}$ ) using the impregnation method, as reported in our previous study [17]. 
The final photocatalyst was denoted as $a \mathrm{Fe}$, where $a$ refers to the amount of Fe i.e., $0.2 \mathrm{Fe}$ refers to $0.2 \mathrm{wt} \% \mathrm{Fe}$ deposited onto $\mathrm{TiO}_{2} / \mathrm{AC}$.

\subsection{Characterization of the Photocatalyst}

Characterization of the photocatalyst was conducted to analyze its physical and chemical properties. The effect of adding AC to the photocatalyst surface was evaluated by analyzing the existing functional group using Fourier transform infrared (FTIR) spectroscopy. The analysis was conducted using a Shimadzu FTIR-8400S Spectrophotometer (Kyoto, Japan). The absorbance and band gap of the photocatalyst was conducted using UV-Visible Spectroscopy. An optical property of the photocatalyst was conducted using an Agilent Technologies Cary 100 UV-Vis Spectrophotometer Model G9821A (Santa Clara, CA, USA). The $\mathrm{pH}_{\mathrm{PZC}}$ of the photocatalyst was employed using the mass titration method, as reported in a previous study [18]. Crystallinity and average particle size analysis of the photocatalyst were conducted using Bruker D8 Advanced XRD (Billerica, MA, USA) with Cu $\mathrm{K} \alpha$ radiation $(40 \mathrm{kV}, 40 \mathrm{~mA})$ at $2 \theta$ angles from $10^{\circ}$ to $80^{\circ}$.

\subsection{Photodegradation Study}

The performance of the developed photocatalyst was evaluated in the photocatalytic degradation of [bmim] $\mathrm{Cl}$ using an open glass reactor in ambient conditions. In a typical experiment, a pre-determined amount of photocatalyst was added into the reactor containing the desired concentration of $[\mathrm{bmim}] \mathrm{Cl}$ solution. The system was stirred in dark for $30 \mathrm{~min}$ to allow for an equilibrium adsorption-desorption process, followed by $2 \mathrm{~h}$ irradiation under a 500-W halogen lamp. Liquid samples were collected at regular time intervals and analyzed using high performance liquid chromatography (Agilent 1100 HPLC, Santa Clara, CA, USA). For better separation and sharp analysis, column symmetry C-18 $(250 \times 4.6 \mathrm{~mm}, 5 \mu \mathrm{m})$ and a mobile phase mixture of methanol ( $35 \mathrm{vol} \%$ ) and $25 \mathrm{mM}$ of phosphate buffer $\left(\mathrm{KH}_{2} \mathrm{PO}_{4} / \mathrm{H}_{3} \mathrm{PO}_{4}\right)$ containing $0.5 \%$ of triethylamine were used. The analysis was performed at a column temperature of $30^{\circ} \mathrm{C}$, a $5-\mu \mathrm{L}$ sample injection, and an $0.8 \mathrm{~mL} / \mathrm{min}$ flow rate. The separated [bmim] $\mathrm{Cl}$ was detected at a 212-nm wavelength using a UV detector (Agilent, Santa Clara, CA, USA)

\section{Results and Discussion}

\subsection{Characterization of the Photocatalysts}

\subsubsection{Fourier Transform Infrared (FTIR)}

Figure 1 shows the vibration peak of different photocatalysts with respect to the Fe content. From the figure, the first broader peak recorded at $766 \mathrm{~cm}^{-1}$ could be ascribed to the titania framework that had been deposited onto the AC, such as Ti-O-Ti $[15,19,20]$. However, the intensity of the vibration IR spectra decreased as the amount of Fe increased. Several studies have reported observations where the IR spectrum of ferric oxide $\left(\mathrm{Fe}_{2} \mathrm{O}_{3}\right)$ between $560-460 \mathrm{~cm}^{-1}$ may have overlapped with the Ti-O-Ti vibration peak at $766 \mathrm{~cm}^{-1}$, causing this peak to diminish as the amount of Fe increased [21,22]. The vibration peak recorded at $1390 \mathrm{~cm}^{-1}$ represented the $\mathrm{C}=\mathrm{O}$ stretching related to carboxylic groups and carboxylate moieties [23,24], while the presence of $\mathrm{C}=\mathrm{O}$ stretching could be due to the oxidation treatment of $\mathrm{AC}$ with nitric acid. This peak was not recorded for lower concentrations of Fe. The same finding was also recorded by Liu et al. in their study where a higher intensity of vibration carbonaceous peaks was recorded only for higher percentages of metal loading [25]. The study also stated that the usage of acid as a treatment agent could produce the homogenous distribution of titania with a complex structure [23]. This can be supported with a vibration peak around $766 \mathrm{~cm}^{-1}$, which shows a strong vibration of $\mathrm{Ti}-\mathrm{O}$, especially for lower amounts of $\mathrm{Fe}$, and proves that complex $\mathrm{TiO}_{2}$ is well distributed on the surface of AC [26].

The small and sharp vibration peaks of $\mathrm{C}-\mathrm{H}$ have been detected in IR spectra at wavenumber $1390 \mathrm{~cm}^{-1}$ and $1478 \mathrm{~cm}^{-1}$. These peaks show that the dissociation of precursor $\mathrm{TiO}_{2} / \mathrm{AC}$ may occur, 
leaving behind other species such as $\mathrm{O}, \mathrm{Ti}$, and $\mathrm{C}$. The presence of the $\mathrm{C}-\mathrm{H}$ bond is also stated to be chemisorbed [27]. Similarly to the $\mathrm{C}=\mathrm{O}$ vibration, the $\mathrm{C}-\mathrm{H}$ peak was not detected for lower amounts of Fe. Meanwhile, the peak at $1640 \mathrm{~cm}^{-1}$ represents the vibration of $\mathrm{O}-\mathrm{H}$ that may have come from the adsorption of $\mathrm{H}_{2} \mathrm{O}$ onto the surface of the photocatalyst $[15,26,27]$. A small peak detected at $2412 \mathrm{~cm}^{-1}$ represents the double bond that may be present on the surface of photocatalysts such as $\mathrm{C}=\mathrm{O}$ [27]. Two close vibration peaks at $2956 \mathrm{~cm}^{-1}$ and $2974 \mathrm{~cm}^{-1}$ also represent the O-H stretching that may be present from the oxidation of AC. This vibration does not appear in IR spectra for low amounts of Fe. The broader peak at $3454 \mathrm{~cm}^{-1}$ represents the $\mathrm{O}-\mathrm{H}$ group $[15,26,27]$. The presence of this broader peak shows the high vibration of $\mathrm{O}-\mathrm{H}$ that exists on the AC's surface, which has been oxidized with nitric acid. This is in line with the purpose of oxidation treatment, which is to obtain a more hydrophilic surface for the photocatalyst with an oxygen-containing functionalized group on the surface of AC, such as the $\mathrm{O}-\mathrm{H}$ group [23]. In the adsorption study of hydrophobic ILs, the presence of $\mathrm{O}-\mathrm{H}$ is important, as it could act as a pollutant concentrator for the composite photocatalyst. The O-H groups that were present on the surface of the photocatalyst were able to promote the $\mathrm{H}$-bonding interactions with the anions of hydrophobic ILs [28,29].

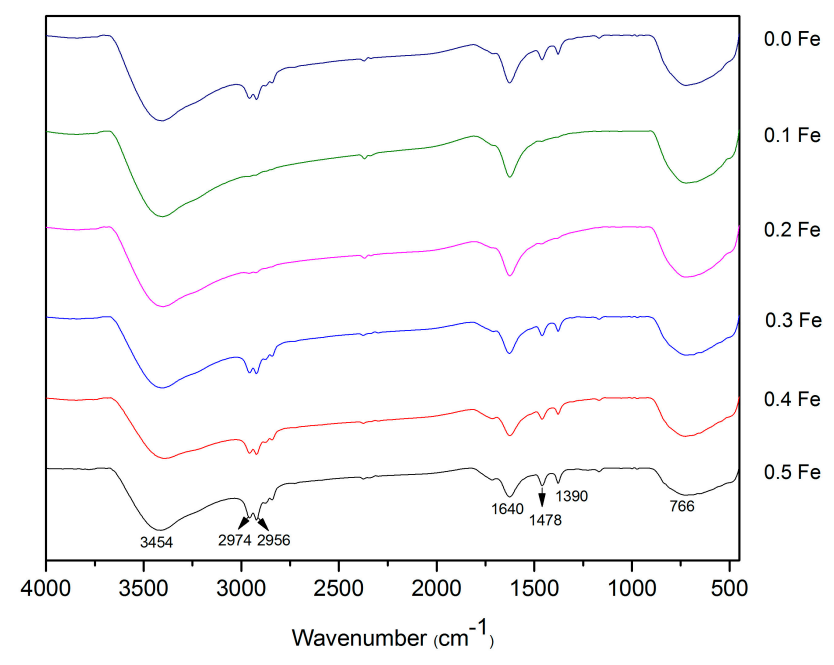

Figure 1. Fourier transform infrared (FTIR) spectra of the photocatalyst at different amounts of Fe.

\subsubsection{Diffuse Reflectance UV-Visible (DRUV-Vis) Analysis}

The absorption spectra of the photocatalysts at different amounts of Fe are presented in Figure 2. From the figure, the absorption edge of $\mathrm{TiO}_{2}$ is at approximately $400 \mathrm{~nm}$, which is correlated to a band-gap energy $\left(\mathrm{E}_{g}\right)$ of $3.10 \mathrm{eV}$. Meanwhile, for the photocatalyst named $0.0 \mathrm{Fe}$ (which is the composite of $\mathrm{TiO}_{2}$ and $\mathrm{AC}$ ), the absorption edge was significantly green-shifted to a 500-nm wavelength corresponding to ca. $2.48 \mathrm{eV}$. The presence of $10 \mathrm{wt} \% \mathrm{AC}$ in the composite has a major role in the reduction of $\mathrm{E}_{g}$, where the powdered photocatalyst was greyish compared to bare $\mathrm{TiO}_{2}$, which is white. On the other hand, the addition of $0.1 \mathrm{wt} \% \mathrm{Fe}$ onto the $\mathrm{TiO}_{2} / \mathrm{AC}$ slightly blue-shifted the absorption edge, which corresponded to an $\mathrm{E}_{g}$ value of $2.88 \mathrm{eV}$. A further shift of the absorption edges could be observed as the amount of Fe loadings increased, with the lowest $\mathrm{E}_{g}$ recorded for the photocatalyst with $0.5 \mathrm{wt} \% \mathrm{Fe}$. The summary of $\mathrm{E}_{g}$ is presented in Table 1.

This observed shift could be ascribed to the excitement of electron $\left(\mathrm{e}_{\mathrm{CB}}^{-}\right)$from the valence band (VB) of $\mathrm{TiO}_{2}$, as described by Equations (1) and (2) [30]. The $\mathrm{h}_{\mathrm{VB}}^{+}$and trapped electron (et) refer to the hole formed at $\mathrm{VB}$ after the excitement of $\mathrm{e}_{\mathrm{CB}}^{-}$, and the electron that had been trapped on the surface AC and metal loading, respectively.

$$
\mathrm{TiO}_{2}+h v \rightarrow \mathrm{TiO}_{2}\left(\mathrm{e}_{\mathrm{CB}}^{-}\right)+\mathrm{TiO}_{2}\left(\mathrm{~h}_{\mathrm{VB}}^{+}\right)
$$




$$
\mathrm{TiO}_{2}\left(\mathrm{e}_{\mathrm{CB}}^{-}\right) \rightarrow \mathrm{TiO}_{2}(\text { et })
$$

The trapped electron could also occur from $\mathrm{e}_{\mathrm{CB}}^{-}$to $\mathrm{Fe}$ on the photocatalyst before the $e$ is excited again to the $\mathrm{TiO}_{2}$ surface, and as a result increase the absorbance value of the UV-Vis (3-6). The $\mathrm{e}^{-}$ refers to the electron from Fe itself.

$$
\begin{gathered}
\mathrm{Fe}^{3+}+\mathrm{TiO}_{2}\left(\mathrm{e}_{\mathrm{CB}}^{-}\right) \rightarrow \mathrm{Fe}^{2+} \\
\mathrm{Fe}^{2+} \rightarrow \mathrm{Fe}^{3+}+\mathrm{TiO}_{2}(e t) \\
\mathrm{Fe}^{3+} \rightarrow \mathrm{Fe}^{4+}+\mathrm{e}^{-} \\
\mathrm{Fe}^{4+}+\mathrm{TiO}_{2}(e t) \rightarrow \mathrm{Fe}^{3+}
\end{gathered}
$$

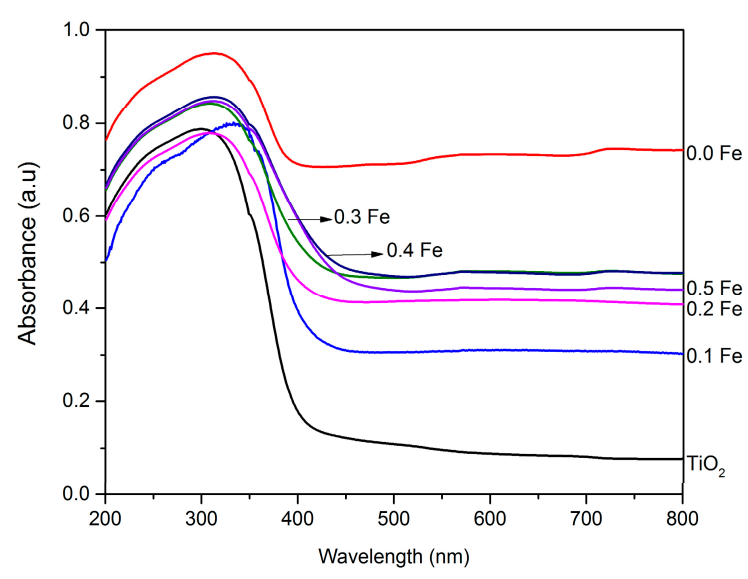

Figure 2. Diffuse reflectance spectra of the photocatalyst.

Table 1. Band-gap energy $\left(\mathrm{E}_{g}\right)$ of the photocatalyst.

\begin{tabular}{cc}
\hline Photocatalyst & Band-Gap Energy, $\mathrm{E}_{\boldsymbol{g}}(\mathbf{e V})$ \\
\hline $\mathrm{TiO}_{2}$ & 3.10 \\
$0.0 \mathrm{Fe}$ & 2.48 \\
$0.1 \mathrm{Fe}$ & 2.88 \\
$0.2 \mathrm{Fe}$ & 2.64 \\
$0.3 \mathrm{Fe}$ & 2.61 \\
$0.4 \mathrm{Fe}$ & 2.39 \\
$0.5 \mathrm{Fe}$ & 2.36 \\
\hline
\end{tabular}

\subsubsection{X-ray Diffraction (XRD)}

Figure 3 depicts the XRD chromatogram for the bare $\mathrm{TiO}_{2}, \mathrm{AC}$, and also the composite photocatalyst.

From Figure 3, a similar pattern of XRD pictograph was recorded for the composite photocatalyst in comparison with bare $\mathrm{TiO}_{2}$. From the figure, it can be clearly observed that both bare and composite $\mathrm{TiO}_{2}$ consist of an anatase structure (98-015-4610) with peaks at $25.3^{\circ}(101), 37.8^{\circ}(111), 48.0^{\circ}(200)$, $55.1^{\circ}(121), 62.7^{\circ}(215), 70.3^{\circ}(220), 75.1^{\circ}(125)$ and $82.7^{\circ}(224)$. The amorphous carbon structure reveals two distinct peaks at $24.6^{\circ}(002)$ and $43.9^{\circ}(110)$, which proves the successful production of AC via the described method in Section 2.2. However, these degrees diminish after depositing $\mathrm{TiO}_{2}$ onto $\mathrm{AC}$, could be due to the dominant peak of anatase $\mathrm{TiO}_{2}$ [31]. In addition, no peak related to $\mathrm{Fe}_{2} \mathrm{O}_{3}$ was detected, even at the highest amount of Fe loading ( $0.5 \mathrm{wt} \%)$, which shows that Fe was uniformly distributed on the $\mathrm{TiO}_{2}$ surface. Furthermore, $\mathrm{Fe}$ and $\mathrm{Ti}$ possess similar ionic radii $(\mathrm{Ti}=0.68 \AA$ and $\mathrm{Fe}=0.64 \AA$ ) $[32,33]$. The mean particle size of the composite photocatalysts was calculated using the 
Scherrer equation [34] at the dominant peak of anatase $(2 \theta=25.3)$. Table 2 summarizes the physical properties of the photocatalyst from XRD analysis.

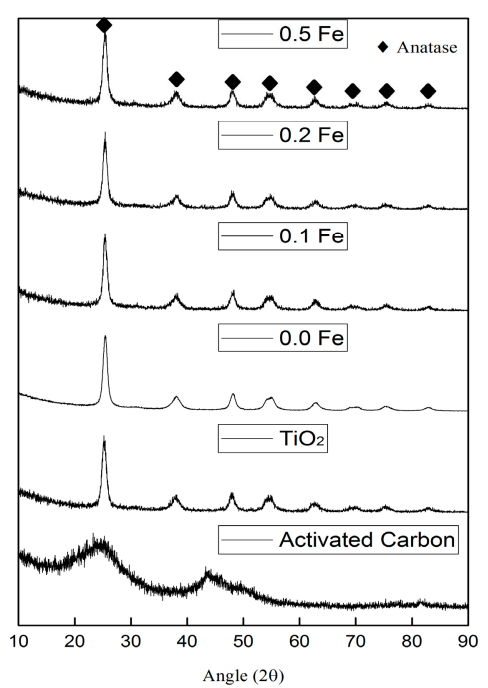

Figure 3. XRD analysis for the photocatalyst with different amounts of Fe content.

Table 2. Particle size of the composite photocatalyst.

\begin{tabular}{ccc}
\hline Photocatalyst & Particle Size (nm) & Crystallographic Constant $(\AA)$ \\
\hline $\mathrm{TiO}_{2}$ & 8.30 & $\mathrm{a}=3.8000, \mathrm{~b}=3.8000, \mathrm{c}=9.4600$ \\
$\mathrm{AC}$ & 29.30 & $\mathrm{a}=2.4700, \mathrm{~b}=2.4700, \mathrm{c}=6.9300$ \\
$0.0 \mathrm{Fe}$ & 24.20 & $\mathrm{a}=3.8000, \mathrm{~b}=3.8000, \mathrm{c}=9.5020$ \\
$0.1 \mathrm{Fe}$ & 10.30 & $\mathrm{a}=3.7850, \mathrm{~b}=3.7850, \mathrm{c}=9.5010$ \\
$0.2 \mathrm{Fe}$ & 10.70 & $\mathrm{a}=3.7850, \mathrm{~b}=3.7850, \mathrm{c}=9.4440$ \\
$0.5 \mathrm{Fe}$ & 11.20 & $\mathrm{a}=3.7850, \mathrm{~b}=3.7850, \mathrm{c}=9.4820$ \\
\hline
\end{tabular}

It is noteworthy to mention that bare $\mathrm{TiO}_{2}$ has the smallest crystallite size, while AC has triple the value. When $\mathrm{TiO}_{2}$ was deposited onto $\mathrm{AC}(0.0 \mathrm{Fe})$, the crystallite size of the photocatalyst was $24.2 \mathrm{~nm}$, similar to the sizes for AC. Adding $0.1 \mathrm{wt} \%$ Fe significantly reduced the crystallite growth by $57 \%$, causing smaller crystals than $0.0 \mathrm{Fe}$. Similar findings were reported by $\mathrm{Li}$ et al., where the particle size of tungsten $\mathrm{W}-\mathrm{TiO}_{2}$ loaded onto $\mathrm{AC}$ was found to be lower than the crystallite size of $\mathrm{TiO}_{2} / \mathrm{AC}$ only. This is because $\mathrm{Fe}^{3+}$ could penetrate into the $\mathrm{Ti}^{4+}$ lattice causing distortion in the structure; thus, it favored the smaller particle size of the photocatalyst, as confirmed by the crystallographic data in Table 2 [35]. The c value for the composite reduced compared to bare $\mathrm{TiO}$, which proved that changes occurred in the crystallographic structure of the composite photocatalysts. A reduction in particle size could govern the photodegradation process, as proven in a previous study [36]. On the other hand, the increasing amount of Fe from $0.1 \mathrm{wt} \%$ to $0.5 \mathrm{wt} \%$ has slightly increased the crystallite size of the photocatalyst, which contradicts with the reported observations from previous studies [35]. The increasing size of the crystals could be due to the agglomeration of $\mathrm{Fe}_{2} \mathrm{O}_{3}$ and $\mathrm{TiO}_{2}$ during the calcination process, yet the amount of $\mathrm{Fe}$ is very low, and highly dispersed on $\mathrm{TiO}_{2}$ for it to be detected by XRD analysis [37].

\subsection{Photodegradation Study}

The photocatalytic activity of the synthesized photocatalyst was evaluated in the photodegradation system of [bmim] Cl under visible light radiation. A 500-W halogen lamp was used to simulate solar light, with the main light spectrum between $400-600 \mathrm{~nm}$. The effect of each 
parameter i.e., the composition of $\mathrm{Fe}$, initial concentration of $[\mathrm{bmim}] \mathrm{Cl}\left(\left[\mathrm{IL}_{\mathrm{o}}\right]\right)$, initial $\mathrm{pH}$ of the solution, and photocatalyst dosage ([photocatalyst]) were evaluated using one-factor-at-a-time (OFAT) method.

\subsubsection{Effect of Fe Composition}

The effect of varying Fe amounts on the total degradation efficiency of the system is summarized in Figure 4. Insignificant degradation was observed when no photocatalyst was added into the system, while only $5 \%$ degradation was recorded in the system containing bare $\mathrm{TiO}_{2}$. Significant enhancement was observed when Fe was added to the photocatalyst. The addition of Fe is crucial to form a space charge layer on the $\mathrm{TiO}_{2}$ surface where upon light radiation, the generated electron $\left(\mathrm{e}_{\mathrm{CB}}^{-}\right)$will be trapped by the $\mathrm{Fe}$, thus preventing it from recombining with the hole $\left(\mathrm{h}_{\mathrm{VB}}^{+}\right)$. Based on the classical field theory, the formation of $\mathrm{Fe}^{2+}$ and $\mathrm{Fe}^{4+}$ is very unstable. This is because in their molecular state $3 \mathrm{~d} 5$ configuration, they are only occupied with half-filled electrons. Hence, the charge carrier then migrated to the surface of $\mathrm{TiO}_{2}$ to degrade $[\mathrm{bmim}] \mathrm{Cl}$. The $\mathrm{Fe}^{2+}$ can be returned back to $\mathrm{Fe}^{3+}$ by donating one $\left(\mathrm{e}_{\mathrm{CB}}^{-}\right)$either directly to $[\mathrm{bmim}] \mathrm{Cl}$ or to $\mathrm{H}_{2} \mathrm{O}$ to undergo a reduction process, producing strong free radicals such as the hydroxyl radical $\left(\bullet^{\bullet} \mathrm{OH}\right)$. These radicals are active species that are able to attack a wide range of organic pollutants, and thus further enhance the degradation rate of pollutants. Meanwhile, $\mathrm{Fe}^{4+}$ can be transformed to $\mathrm{Fe}^{3+}$ by receiving an electron or losing a hole $\left(\mathrm{h}_{\mathrm{VB}}^{+}\right)$. The $\mathrm{h}_{\mathrm{VB}}^{+}$ will come into contact with the oxygen $\left(\mathrm{O}_{2}\right)$ that has also been adsorbed on the surface of $\mathrm{TiO}_{2}$, leading to the formation of the superoxide radical $\left(\mathrm{O}_{2}^{-\bullet}\right)[14,38]$. During the degradation process of [bmim $] \mathrm{Cl}$, the $\mathrm{O}_{2}^{-\bullet}$ will attack $\mathrm{C} 2, \mathrm{C} 4$, and $\mathrm{C} 5$ of the imidazolium ring to produce an unstable by-product known as 1-alkyl-3-methyl-2,4,5-trioxoimidazolidine. The formation of these by-products means that the first stage of the degradation process where the phenomenon opening ring of cation occurred [39].

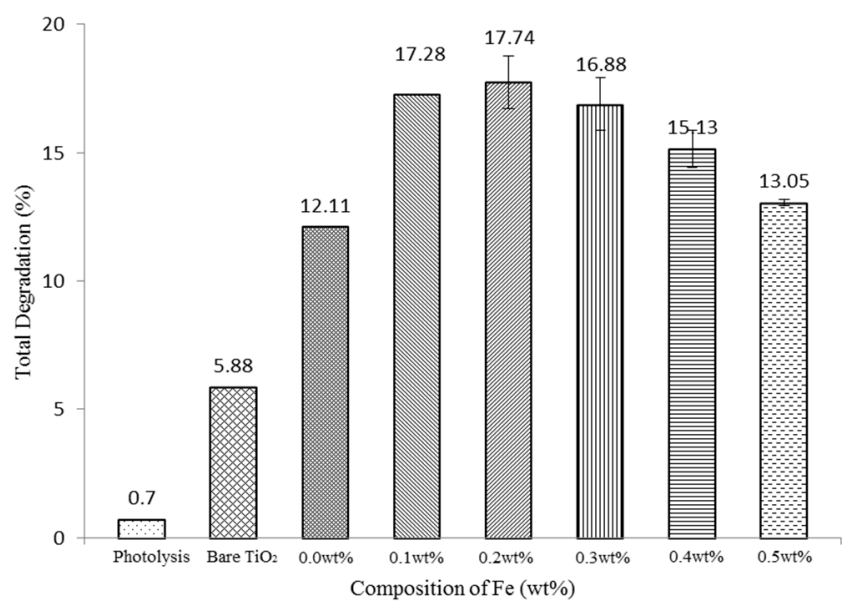

Figure 4. Efficiency of [bmim $] \mathrm{Cl}$ photodegradation system with different compositions of Fe; $\left[\mathrm{IL}_{\mathrm{o}}\right]=5 \mathrm{mM}, \mathrm{pH}=8$ and [photocatalyst $]=1 \mathrm{~g} / \mathrm{L}$.

Further increasing the amount of Fe from $0.1 \mathrm{wt} \%$ to $0.2 \mathrm{wt} \%$ increased the surface barrier and lead to the optimum separation of the $\mathrm{e}_{\mathrm{CB}}^{-}-\mathrm{h}_{\mathrm{VB}}^{+}$pairs. However, when the amount of Fe was increased beyond its optimum amount, the overall efficiency of the system decreased. Even though the higher amount of Fe further reduced the band-gap energy of $\mathrm{TiO}_{2}$ (Table 1), it also acted as the recombination center for the charge carriers. The excess amount of Fe reversed its positive role and become the recombination sites for the $\mathrm{e}_{\mathrm{CB}}^{-}-\mathrm{h}_{\mathrm{VB}}^{+}$pairs, thus preventing them from taking part in the degradation process [40]. Similar findings have been discussed by other researchers, where higher $\mathrm{Fe}$ contents could produce more Fe clusters on the $\mathrm{TiO}_{2}$ surface, as seen in Equations (3)-(6) [41]. The formation of $\mathrm{Fe}_{2} \mathrm{O}_{3}$ could correlate with IR spectra (Figure 1), as the Ti-O-Ti vibration was slightly diminish at higher amounts of $\mathrm{Fe}$ due to overlapping with the $\mathrm{Fe}_{2} \mathrm{O}_{3}$ that was recorded from $464 \mathrm{~cm}^{-1}$ to $700 \mathrm{~cm}^{-1}$. The formation of an oxygenated group on the surface of the composite photocatalyst 
(Figure 1) also played an important role in the degradation of [bmim $] \mathrm{Cl}$. The presence of functionalized groups such as $\mathrm{O}-\mathrm{H}$ is believed to be able to increase the interaction of $\mathrm{H}$-bonding between the surface of the composite photocatalyst and the anion $\mathrm{Cl}$ [29]. Hence, more [bmim] $\mathrm{Cl}$ will be attracted to the $\mathrm{AC}$ on the $\mathrm{TiO}_{2}$ surface, which then enhances the diffusion rate between [bmim]Cl and the surface $\mathrm{TiO}_{2}$, resulting in a significant increase in the total removal of $[\mathrm{bmim}] \mathrm{Cl}$. At the same time, the diminished carbonaceous peak for lower Fe loadings $\left(1390 \mathrm{~cm}^{-1}\right)$ also may enhance the activity of the photocatalyst, as presence of this peak could reduce the catalytic property of the photocatalyst [42]. This clearly can be seen from Figure 4, where both 0.1Fe and 0.2Fe show slightly a higher removal of bmim $[\mathrm{Cl}]$ compared with the other photocatalyst, as the carbonaceous peak does not present for both photocatalysts.

\subsubsection{Effect of Extrinsic Factor: Initial Concentration of $[\mathrm{bmim}] \mathrm{Cl}\left(\mathrm{IL}_{\mathrm{o}}\right)$}

Figure 5 presents the effect of the initial concentration of $[\mathrm{bmim}] \mathrm{Cl}\left(\left[\mathrm{IL}_{\mathrm{o}}\right]\right)$ on the overall performance of the system. The study was conducted by keeping other parameters constant i.e., $0.2 \mathrm{wt} \% \mathrm{Fe}$, with initial $\mathrm{pH}$ at 8 and $1 \mathrm{~g} / \mathrm{L}$ of photocatalyst. In general, the overall degradation efficiency decreased with the increase of $\left[\mathrm{IL}_{\mathrm{o}}\right]$. At lower concentrations, a sufficient active site on the photocatalyst for optimal adsorption and degradation processes lead to the higher overall efficiency of the system. However, as the concentration of [bmim] $\mathrm{Cl}$ increased, the number of [bmim] $\mathrm{Cl}$ molecules in the solution consequently increased, causing lower absorption of photons and lower degradation rate on the surface of the photocatalyst due to insufficient active sites. On the other hand, at lower [ $\mathrm{IL}_{\mathrm{o}}$ ], the accumulation of the pollutant on the surface of $\mathrm{TiO}_{2}$ reduced, providing a more active surface area to absorb the photons and generate the charge carrier. As more charge carriers are generated, more [bmim $] \mathrm{Cl}$ can be degraded. This phenomenon follows the Lambert law, whereas the concentration of organic molecules reduced, the path length taken by the photon to enter the solutions increased [43].

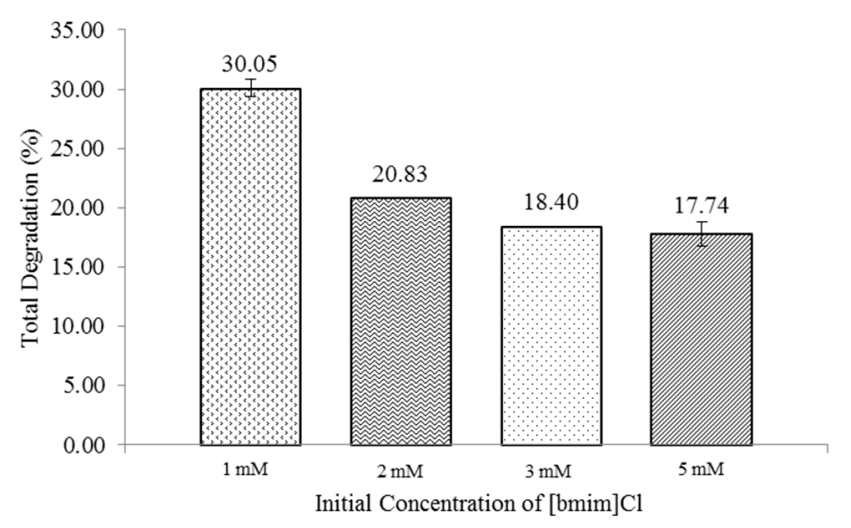

Figure 5. Efficiency of $[\mathrm{bmim}] \mathrm{Cl}$ photodegradation system at different $\left[\mathrm{IL}_{\mathrm{o}}\right]$.

\subsubsection{Effect of Extrinsic Factor: Initial $\mathrm{pH}$ of the [bmim]Cl Solution}

The point zero charge $\left(\mathrm{pH}_{\mathrm{pzc}}\right)$ of the photocatalyst can be defined as the limiting $\mathrm{pH}$ when the net surface charge of the photocatalyst is zero. The $\mathrm{pH}_{\mathrm{pzc}}$ value of the photocatalyst was determined using the titration method as reported in a previous study [18].

Pursuant to Section 3.2.2, optimum $\left[\mathrm{IL}_{\mathrm{o}}\right]$ was observed at $1 \mathrm{mM}$. Hence, this $\left[\mathrm{IL}_{\mathrm{o}}\right]$ has been selected to study the effect of the initial $\mathrm{pH}$ of the $[\mathrm{bmim}] \mathrm{Cl}$ solution, while keeping other parameters constant i.e., $0.2 \mathrm{wt} \% \mathrm{Fe},\left[\mathrm{IL}_{\mathrm{o}}\right]$ at $1 \mathrm{mM}$, and $1 \mathrm{~g} / \mathrm{L}$ of photocatalyst. Figure 6 depicts the comparative study on the $\mathrm{pH}$ of the $[\mathrm{bmim}] \mathrm{Cl}$ solution. As the initial solution's $\mathrm{pH}$ increased, the total removal of $[\mathrm{bmim}] \mathrm{Cl}$ increased until the optimum point, and then decreased. The lowest [bmim] $\mathrm{Cl}$ degradation was recorded in an acidic region at $\mathrm{pH}$ 3. In an acidic region, the surface charges of the photocatalyst and organic molecule were both protonated. The similar charges between both species made them 
repel each other, causing less adsorbate to be adsorbed onto the surface of the photocatalyst. Further, this also caused a lower amount of [bmim] $\mathrm{Cl}$ to be degraded by the charge carrier [44]. In addition, the photocatalyst was reported to be agglomerated in acidic conditions, thus reducing the availability of the $\mathrm{TiO}_{2}$ active site that can be used to absorb photons and adsorb [bmim]Cl [45]. From the study, the best working $\mathrm{pH}$ for the photodegradation of $[\mathrm{bmim}] \mathrm{Cl}$ was recorded in alkaline condition at $\mathrm{pH}$ 10. In this condition, the $\mathrm{OH}^{-}$interacted with $\mathrm{h}_{\mathrm{VB}}^{+}$, leading to the higher production of ${ }^{\bullet} \mathrm{OH}$, and thus increased the degradation rate of [bmim] $\mathrm{Cl}$. However, at even higher alkalinity, both the organic molecules and the surface of the photocatalyst were deprotonated. The similar charges of both species again repelled each other, causing less [bmim] $\mathrm{Cl}$ to be adsorbed on the surface of $\mathrm{TiO}_{2}$, and hence reducing the total degradation [44]. This ionization of the surface charge photocatalyst in various $\mathrm{pH}$ conditions could be explained as in Equations (7) and (8) [9].

It can be observed that the pHpzc of the photocatalyst is 6.3 (Figure 7). On the other hand, the $\mathrm{pH}$ of the [bmim $] \mathrm{Cl}$ solution was recorded around $8.2 \pm 0.2$, regardless of the [bmim]Cl concentration. Generally, when the $\mathrm{pH}$ of the solution is higher than the $\mathrm{pH}_{\mathrm{pzc}}$ of the photocatalyst, the surface of the photocatalyst will be negatively charged. Different charges between the photocatalyst surface and [bmim $] \mathrm{Cl}$ will attract each other, hence increase the diffusion rate of $[\mathrm{bmim}] \mathrm{Cl}$ into $\mathrm{TiO}_{2}$ [9]. On the other hand, similar charges between both entities will reduce the ability of $\mathrm{TiO}_{2}$ to attract the $[\mathrm{bmim}] \mathrm{Cl}$ compound toward its surface.

$$
\begin{gathered}
\mathrm{TiOH}+\mathrm{H}^{+} \rightarrow \mathrm{TiOH}_{2}{ }^{+} \\
\mathrm{TiOH}+\mathrm{OH}^{-} \rightarrow \mathrm{TiO}^{-}+\mathrm{H}_{2} \mathrm{O}
\end{gathered}
$$

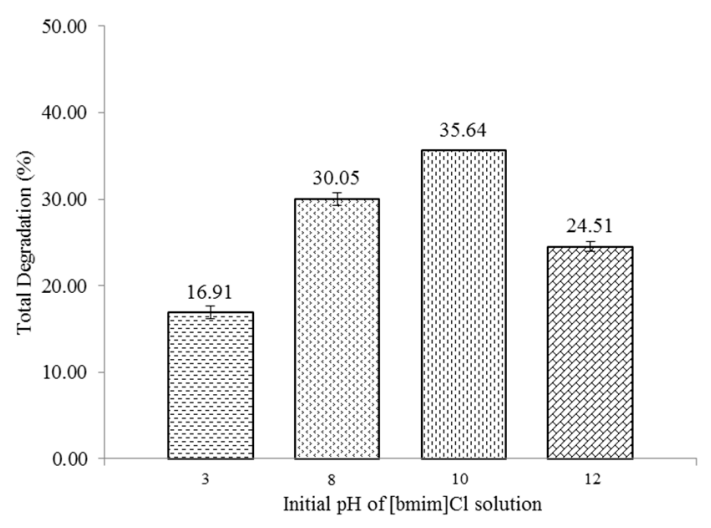

Figure 6. Efficiency of [bmim $] \mathrm{Cl}$ photodegradation system at different initial $\mathrm{pH}$ of $[\mathrm{bmim}] \mathrm{Cl}$ solution.

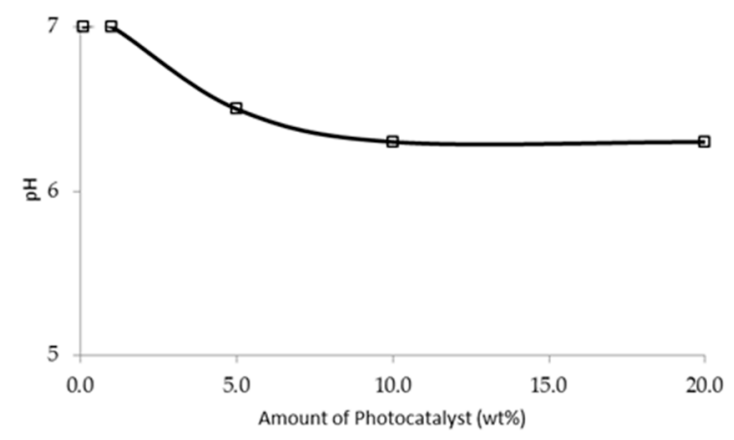

Figure 7. Surface charge of the photocatalyst $0.2 \mathrm{Fe}-\mathrm{TiO}_{2} / \mathrm{AC}$.

\subsubsection{Effect of Extrinsic Factor: Dosage of Photocatalyst [Photocatalyst]}

The effect of the photocatalyst dosage [photocatalyst] on the efficiency of the system was evaluated by keeping other factors constant i.e., $0.2 \mathrm{wt} \% \mathrm{Fe}$, $\left[\mathrm{IL}_{\mathrm{o}}\right]$ at $1 \mathrm{mM}$, and initial $\mathrm{pH} 10$. Figure 8 summarizes 
the removal efficiency at different [photocatalyst]; as can be observed from the figure, [photocatalyst] has a significant effect on the total removal of [bmim]Cl. The effect of the photocatalyst dosage [photocatalyst] on the overall efficiency of the photodegradation system of [bmim] $\mathrm{Cl}$ was studied by varying the [photocatalyst] between $0.0-8 \mathrm{~g} / \mathrm{L}$. From Figure 8 , the total degradation of [bmim]Cl increased until the optimum [photocatalyst] was achieved. Insufficient amount of photocatalyst supplied to the system will cause a blockage of the active site by $[\mathrm{bmim}] \mathrm{Cl}$, causing poor efficiency of the system [46]. As the dosage increased, the active sites available for the photodegradation process also increased, leading to a higher degradation rate. Beyond the optimum dosage ( $>1 \mathrm{~g} / \mathrm{L})$, the overall efficiency of the system decreased despite a larger amount of photocatalyst being used in the system. A high amount of photocatalyst in the system lead to the screening phenomenon of particles, which will cause blockages of the active sites of the photocatalyst. Furthermore, excess amount of photocatalyst leads to agglomeration of the nanoparticles, thus reduces total surface area of the photocatalyst which then lead to lesser photon absorption [47].

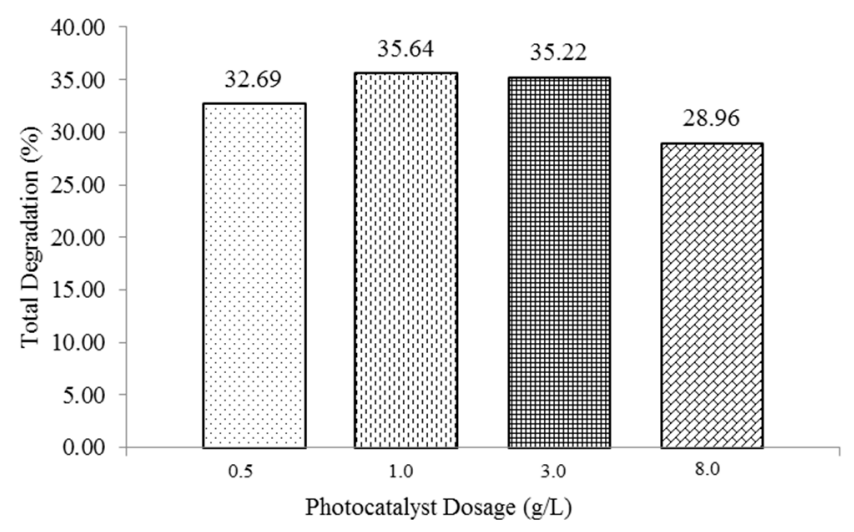

Figure 8. Efficiency of [bmim $] \mathrm{Cl}$ degradation system at different [photocatalyst].

\section{Conclusions}

Optimum amount of Fe in the preparation of photocatalyst is crucial as it could directly affect the efficiency of the system. From the analysis study of composition Fe loaded onto $\mathrm{TiO}_{2}$, it can be concluded that incorporating an optimum amount of metal onto the surface of $\mathrm{TiO}_{2}$ can shift the performance of $\mathrm{TiO}_{2}$ into the visible region, and increase the performance of the photocatalyst for the removal of [bmim] Cl. Apart from Fe, concentration of the compound of interest, in this case, [bmim] $\mathrm{Cl}$ also is important. Excess $\left[\mathrm{IL}_{\mathrm{o}}\right]$ in the system will block the surface of $\mathrm{TiO}_{2}$ from harvesting the light, thus causing lower overall efficiency. Optimum $\mathrm{pH}$ for the system to work at the highest efficiency was recorded at $\mathrm{pH} 10$. At this condition, the available ${ }^{-} \mathrm{OH}$ will increase the production of ${ }^{\bullet} \mathrm{OH}$ as the attacking agent that will increase the total degradation of [bmim]Cl. Finally, optimum amount of photocatalyst itself is also critical as excess photocatalyst dosage will cause agglomeration leading to lesser active sites of the photocatalyst for further process.

Acknowledgments: Special thanks to Universiti Teknologi PETRONAS (UTP) for funding from I-Gen Grant (IGEN 0153 DA-162) and Centralize Analytical Laboratory (CAL), UTP for the characterization analysis.

Author Contributions: Azhar Zawawi and Raihan Mahirah Ramli conceived and designed the experiments; Azhar Zawawi performed the experiments; Azhar Zawawi and Raihan Mahirah Ramli and Noorfidza Yub Harun analyzed the data; Raihan Mahirah Ramli and Noorfidza Yub Harun contributed reagents/materials/analysis tools; Azhar Zawawi wrote the paper. All authors have read and approved the final manuscript.

Conflicts of Interest: The founding sponsors had no role in the design of the study; in the collection, analyses, or interpretation of data; in the writing of the manuscript, and in the decision to publish the results. 


\section{References}

1. Olivier-Bourbigou, H.; Magna, L.; Morvan, D. Ionic liquids and catalysis: Recent progress from knowledge to applications. Appl. Catal. A Gen. 2010, 373,1-56. [CrossRef]

2. Plechkova, N.V.; Seddon, K.R. Applications of ionic liquids in the chemical industry. Chem. Soc. Rev. 2008, 37, 123-150. [CrossRef] [PubMed]

3. Siedlecka, E.M.; Fabiańska, A.; Stolte, S.; Nienstedt, A.; Ossowski, T.; Stepnowski, P.; Thöming, J. Electrocatalytic Oxidation of 1-Butyl-3-Methylimidazolium Chloride: Effect of the Electrode Material. Int. J. Electrochem. Sci. 2013, 8, 5560-5574.

4. Munoz, M.; Domínguez, C.M.; de Pedro, Z.M.; Quintanilla, A.; Casas, J.A.; Rodriguez, J.J. Ionic liquids breakdown by Fenton oxidation. Catal. Today 2015, 240, 16-21. [CrossRef]

5. Zhou, H.; Shen, Y.; Lv, P.; Wang, J.; Li, P. Degradation pathway and kinetics of 1-alkyl-3-methylimidazolium bromides oxidation in an ultrasonic nanoscale zero-valent iron/hydrogen peroxide system. J. Hazard. Mater. 2015, 284, 241-252. [CrossRef] [PubMed]

6. Buthiyappan, A.; Abdul Aziz, A.R.; Wan Daud, W.M.A. Recent advances and prospects of catalytic advanced oxidation process in treating textile effluents. Rev. Chem. Eng. 2016, 32, 1-47. [CrossRef]

7. Ramli, R.M.; Chong, F.K.; Omar, A.A. Visible-Light Photodegradation of Diisopropanolamine Using Bimetallic Cu-Fe/ $\mathrm{TiO}_{2}$ Photocatalyst. Adv. Mater. Res. 2013, 845, 421-425. [CrossRef]

8. Ramli, R.M.; Kait, C.F.; Omar, A.A. Remediation of DIPA contaminated wastewater using visible light active bimetallic $\mathrm{Cu}-\mathrm{Fe} / \mathrm{TiO}_{2}$ Photocatalyst. Procedia Eng. 2016, 148, 508-515. [CrossRef]

9. Saepurahman; Abdullah, M.A.; Chong, F.K. Preparation and characterization of tungsten-loaded titanium dioxide photocatalyst for enhanced dye degradation. J. Hazard. Mater. 2010, 176, 451-458. [CrossRef] [PubMed]

10. Ramli, R.M.; Kait, C.F.; Omar, A.A. Photodegradation of aqueous diisopropanolamine using Cu/ $\mathrm{TiO}_{2}$ : $\mathrm{Effect}$ of calcination temperature and duration. Appl. Mech. Mater. 2014, 625, 847-850. [CrossRef]

11. Orha, C.; Pode, R.; Manea, F.; Lazau, C.; Bandas, C. Titanium dioxide-modified activated carbon for advanced drinking water treatment. Process Saf. Environ. Prot. 2016, 108, 26-33. [CrossRef]

12. Sampaio, M.J.; Pastrana-Martinez, L.M.; Silva, A.M.T.; Buijnsters, J.G.; Han, C.; Silva, C.G.; Carabineiro, S.A.C.; Dionysiou, D.D.; Faria, J.L. Nanodiamond-TiO ${ }_{2}$ composites for photocatalytic degradation of microcystin-LA in aqueous solutions under simulated solar light. RSC Adv. 2015, 5, 58363-58370. [CrossRef]

13. Pastrana-Martínez, L.M.; Morales-Torres, S.; Carabineiro, S.A.C.; Buijnsters, J.G.; Faria, J.L.; Figueiredo, J.L.; Silva, A.M.T. Nanodiamond- $\mathrm{TiO}_{2}$ Composites for Heterogeneous Photocatalysis. ChemPlusChem 2013, 78, 801-807. [CrossRef]

14. Zhang, D. Enhanced photocatalytic activity for titanium dioxide by co-modification with copper and iron. Transit. Met. Chem. 2010, 35, 933-938. [CrossRef]

15. Zhou, W.; Zhang, P.; Liu, W. Anatase $\mathrm{TiO}_{2}$ Nanospindle/ActivatedCarbon (AC) Composite Photocatalysts with Enhanced Activity in Removal of Organic Contaminant. Int. J. Photoenergy 2012. [CrossRef]

16. Ozkal, C.B.; Koruyucu, A.; Meric, S. Heterogeneous photocatalytic degradation, mineralization and detoxification of ampicillin under varying $\mathrm{pH}$ and incident photon flux conditions. Desalin. Water Treat. 2016, 57, 18391-18397. [CrossRef]

17. Zawawi, A.; Ramli, R.M.; Harun, N.Y. Synergistic Effect Of Adsorption-Photodegradation Of Composite $\mathrm{TiO}_{2}$ / AC For Degradation Of 1-Butyl-3-Methylimidazolium Chloride. Malays. J. Anal. Sci. 2017, in press.

18. Di Paola, A.; García-López, E.; Marcì, G.; Martín, C.; Palmisano, L.; Rives, V.; Maria Venezia, A. Surface characterisation of metal ions loaded $\mathrm{TiO}_{2}$ photocatalysts: structure-activity relationship. Appl. Catal. B Environ. 2004, 48, 223-233. [CrossRef]

19. Alalm, M.G.; Tawfik, A.; Ookawara, S. Enhancement of photocatalytic activity of $\mathrm{TiO}_{2}$ by immobilization on activated carbon for degradation of pharmaceuticals. J. Environ. Chem. Eng. 2016, 4, 1929-1937. [CrossRef]

20. Muhamma, A.S.; Naser, J.T.; Kirm, I.; Jibril, B.Y. Photocatalytic Degradation of Methylene Blue and Phenol Using $\mathrm{TiO}_{2}$ / Activated-Carbon Composite Catalysts. Asian J. Chem. 2015, 1, 343-348. [CrossRef]

21. Sahoo, S.K.; Agarwal, K.; Singh, A.K.; Polke, B.G.; Raha, K.C. Characterization of $\gamma$ - and $\alpha-\mathrm{Fe}_{2} \mathrm{O}_{3}$ nano powders synthesized by emulsion precipitation-calcination route and rheological behaviour of $\alpha-\mathrm{Fe}_{2} \mathrm{O}_{3}$. Int. J. Eng. Sci. Technol. 2010, 2, 118-126. 
22. Wang, Y.; Muramatsu, A.; Sugimoto, T. FTIR analysis of well-defined $\alpha-\mathrm{Fe}_{2} \mathrm{O}_{3}$ particles. Colloids Surf. A Physicochem. Eng. Asp. 1998, 134, 281-297. [CrossRef]

23. Oh, W.C.; Chen, M.L. Formation of $\mathrm{TiO}_{2}$ composites on activated carbon modified by nitric acid and their photocatalytic activity. J. Ceram. Process. Res. 2007, 8, 316-323.

24. Wang, X.; Liu, Y.; Hu, Z.; Chen, Y.; Liu, W.; Zhao, G. Degradation of methyl orange by composite photocatalysts nano- $\mathrm{TiO}_{2}$ immobilized on activated carbons of different porosities. J. Hazard. Mater. 2009, 169, 1061-1067. [CrossRef] [PubMed]

25. Liu, D.; Wu, Z.; Tian, F.; Ye, B.-C.; Tong, Y. Synthesis of $\mathrm{N}$ and La co-doped $\mathrm{TiO}_{2} / \mathrm{AC}_{\text {photocatalyst by }}$ microwave irradiation for the photocatalytic degradation of naphthalene. J. Alloys Compd. 2016, 676, 489-498. [CrossRef]

26. Zhang, Z.; Xu, Y.; Ma, X.; Li, F.; Liu, D.; Chen, Z.; Zhang, F.; Dionysiou, D.D. Microwave degradation of methyl orange dye in aqueous solution in the presence of nano- $\mathrm{TiO}_{2}$-supported activated carbon (supported-TiO 2 / AC/MW). J. Hazard. Mater. 2012, 209-210, 271-277. [CrossRef] [PubMed]

27. Andronic, L.; Enesca, A.; Cazan, C.; Visa, $\mathrm{M}$. $\mathrm{TiO}_{2}$-active carbon composites for wastewater photocatalysis. J. Sol-Gel Sci. Technol. 2014, 71, 396-405. [CrossRef]

28. Lemus, J.; Neves, C.M.; Marques, C.F.; Freire, M.G.; Coutinho, J.A.; Palomar, J. Composition and structural effects on the adsorption of ionic liquids onto activated carbon. Environ. Sci. Process Impacts 2013, 15, 1752-1759. [CrossRef] [PubMed]

29. Lemus, J.; Palomar, J.; Heras, F.; Gilarranz, M.A.; Rodriguez, J.J. Developing criteria for the recovery of ionic liquids from aqueous phase by adsorption with activated carbon. Sep. Purif. Technol. 2012, 97, 11-19. [CrossRef]

30. Huang, D.; Miyamoto, Y.; Matsumoto, T.; Tojo, T.; Fan, T.; Ding, J.; Guo, Q.; Zhang, D. Preparation and characterization of high-surface-area $\mathrm{TiO}_{2}$ /activated carbon by low-temperature impregnation. Sep. Purif. Technol. 2011, 78, 9-15. [CrossRef]

31. Xing, B.; Shi, C.; Zhang, C.; Yi, G.; Chen, L.; Guo, H.; Huang, G.; Cao, J. Preparation of TiO 2 /Activated Carbon Composites for Photocatalytic Degradation of RhB under UV Light Irradiation. J. Nanomater. 2016. [CrossRef]

32. Qamar, M.; Merzougui, B.; Anjum, D.; Hakeem, A.S.; Yamani, Z.H.; Bahnemann, D. Synthesis and photocatalytic activity of mesoporous nanocrystalline Fe-doped titanium dioxide. Catal. Today 2014, 230, 158-165. [CrossRef]

33. Nasralla, N.; Yeganeh, M.; Astuti, Y.; Piticharoenphun, S.; Shahtahmasebi, N.; Kompany, A.; Karimipour, M.; Mendis, B.G.; Poolton, N.R.J.; Šiller, L. Structural and spectroscopic study of Fe-doped $\mathrm{TiO}_{2}$ nanoparticles prepared by sol-gel method. Sci. Iran. 2013, 20, 1018-1022.

34. Yan, K.; Wu, G.; Jarvis, C.; Wen, J.; Chen, A. Facile synthesis of porous microspheres composed of $\mathrm{TiO}_{2}$ nanorods with high photocatalytic activity for hydrogen production. Appl. Catal. B Environ. 2014, 148, 281-287. [CrossRef]

35. Li, Y.; Zhou, X.; Chen, W.; Li, L.; Zen, M.; Qin, S.; Sun, S. Photodecolorization of Rhodamine B on tungsten-doped $\mathrm{TiO}_{2}$ /activated carbon under visible-light irradiation. J. Hazard. Mater. 2012, 227, 25-33. [CrossRef] [PubMed]

36. Yan, K.; Wu, G. Titanium Dioxide Microsphere-Derived Materials for Solar Fuel Hydrogen Generation. ACS Sustain. Chem. Eng. 2015, 3, 779-791. [CrossRef]

37. Choi, H.-J.; Kang, M. Hydrogen production from methanol/water decomposition in a liquid photosystem using the anatase structure of $\mathrm{Cu}$ loaded $\mathrm{TiO}_{2}$. Int. J. Hydrogen Energy 2007, 32, 3841-3848. [CrossRef]

38. Obregón, S.; Lee, S.W.; Rodríguez-González, V. Loading effects of silver nanoparticles on hydrogen photoproduction using a $\mathrm{Cu}-\mathrm{TiO}_{2}$ photocatalyst. Mater. Lett. 2016, 173, 174-177. [CrossRef]

39. Siedlecka, E.M.; Mrozik, W.; Kaczynski, Z.; Stepnowski, P. Degradation of 1-butyl-3-methylimidazolium chloride ionic liquid in a Fenton-like system. J. Hazard. Mater. 2008, 154, 893-900. [CrossRef] [PubMed]

40. Tan, Y.N.; Wong, C.L.; Mohamed, A.R. An Overview on the Photocatalytic Activity of Nano-Doped-TiO 2 in the Degradation of Organic Pollutants. ISRN Mater. Sci. 2011, 1-18. [CrossRef]

41. Melcher, J.; Feroz, S.; Bahnemann, D. Comparing photocatalytic activities of commercially available iron-doped and iron-undoped aeroxide $\mathrm{TiO}_{2}$ P25 powders. J. Mater. Sci. 2017, 52, 6341-6348. [CrossRef]

42. Senee, K.; Ratchaneekorn, W. Studies on preparation and characterization of $\mathrm{Fe} / \mathrm{TiO}_{2}$ catalyst in photocatalysis applications. Mater. Res. Express 2017, 4, 076507. 
43. Hassena, $\mathrm{H}$. Photocatalytic Degradation of Methylene Blue by Using $\mathrm{Al}_{2} \mathrm{O}_{3} / \mathrm{Fe}_{2} \mathrm{O}_{3}$ Nano Composite under Visible Light. Mod. Chem. Appl. 2016, 176. [CrossRef]

44. Alkaim, A.F.; Kandiel, T.A.; Hussein, F.H.; Dillert, R.; Bahnemann, D.W. Enhancing the photocatalytic activity of $\mathrm{TiO}_{2}$ by $\mathrm{pH}$ control: a case study for the degradation of EDTA. Catal. Sci. Technol. 2013, 3, 3216-3222. [CrossRef]

45. Akpan, U.G.; Hameed, B.H. Parameters affecting the photocatalytic degradation of dyes using $\mathrm{TiO}_{2}$-based photocatalysts: a review. J. Hazard. Mater. 2009, 170, 520-529. [CrossRef] [PubMed]

46. Andriantsiferana, C.; Mohamed, E.F.; Delmas, H. Photocatalytic degradation of an azo-dye on $\mathrm{TiO}_{2} /$ activated carbon composite material. Environ. Technol. 2013, 35, 355-363. [CrossRef] [PubMed]

47. Belver, C.; Bedia, J.; Álvarez-Montero, M.A.; Rodriguez, J.J. Solar photocatalytic purification of water with Ce-doped $\mathrm{TiO}_{2}$ / clay heterostructures. Catal. Today 2016, 266, 36-45. [CrossRef]

(C) 2017 by the authors. Licensee MDPI, Basel, Switzerland. This article is an open access article distributed under the terms and conditions of the Creative Commons Attribution (CC BY) license (http:/ / creativecommons.org/licenses/by/4.0/). 